\title{
Oncological and functional results of the surgical treatment of vertebral metastases in patients with multiple myeloma"
}

\author{
Grzegorz Guzik ${ }^{1,2}$
}

\begin{abstract}
Background: In nearly $30 \%$ of patients with myeloma, pathological fractures are found to occur in the spine. If the patients are not treated promptly and satisfactorily, the quality of their lives diminishes. Currently, the standard treatment for metastatic lesions of the spine is radiotherapy, but surgical intervention is becoming more frequent. It is very important to quickly identify metastases and implement surgical treatment before any fracture/s occur.
\end{abstract}

Methods: Over the period of 2010-2014 in our department, a total of 129 patients were treated for metastatic spinal myeloma. 73 patients underwent vertebroplasty and 56 patients were operated on through various methods. Indications for the surgery, its course, technique and outcome were subsequently evaluated. The majority of patients (76\%) admitted for treatment, exhibited vertebral fractures. Most lesions were multiplace and involved the vertebral bodies. In $42 \%$ of the patients, radiological examinations showed symptoms of compression of the nervous structures, while clinical signs were observed in only $16 \%$ of the patients. The functional status of the patients was assessed using the Karnofsky scale, while pain intensity was measured in a VAS score, before and after the surgery. The oncological results were assessed as a survival rate and local recurrence rate.

Results: The average follow-up was conducted within 31 months (min 18, max 48). The patients after vertebroplasty survived 42 months, and the patients after surgery 23 months. Local recurrence of the disease was observed in 12 patients. In 10 patients, among a group of 21 with paresis, their neurological conditions improved. The average results of both their VAS score and Karnofsky performance score in patients after surgery was seen to have improved. Only sporadic postoperative complications after vertebroplasty and surgery were reported.

Conclusions: Early diagnosis of myeloma spine metastasis is essential to achieve the desired results of treatment. Vertebroplasty, as advised, should be performed as early as possible. Both the functional and oncological results after vertebroplasty are beneficial and the complication rates are low. Three relevant factors were found in our study: patient's age over 65 years, initial diagnosis over 3 years and stage III of disease were related, significantly and statistically to survival.

Keywords: Metastases, Spinal tumours, Spine surgery, Resections, Stabilization, Multiple myeloma

\footnotetext{
Correspondence: grzegorz.guzik@vp.pl

${ }^{1}$ Orthopedic Oncology Department of the Podkarpacki Oncology Hospital,

Bielawskiego 18, 36-200 Brzozów, Poland

Dworska 77a, 38-420 Korczyna, Poland
} 


\section{Background}

Effective oncological treatment significantly prolonged the life expectancy of patients with multiple myeloma (MM). It is estimated that approximately $70 \%$ of sufferers have osteolytic lesions in the spine, and in 30\% of these pathological fractures occur. Spinal cord compression is reported to develop in $11-24 \%$ of patients with MM [1-3].

The quality of life in patients suffering from spinal fractures is significantly decreased. Patients experience acute pain and their mobility is significantly reduced. They oftens use walking frames or crutches. Among patients with vertebral column involvement, three type of pain can be distinguished, according to such characteristical features such as: localization, radiation and exacerbating factors. Mechanical pain is associated with an instability of the vertebral column. It is a localized, sharp pain, exacerbated in the standing position, and frequently alleviated after stabilization in an orthopedic corset. Biological pain is unremitting, worse in the supine position, less posture-dependent, unresponsive to medication and more noticeable at night. Damage to the body neurons results in neuropathic pain, which is often described as shooting, traveling along the nerves. Spinal axis disorder creates the risk of adjacent vertebrae syndrom. In some patients, numerous neurological disorders may coexist. [4-6]

The treatment of multiple myeloma is a combination of chemotherapy and radiotherapy. The ultimate goal of the treatment is to achieve remission or stability of the disease. Radiotherapy of the bone and the metastases causes a decrease in the number of local recurrence and pain. However, radiotherapy alone cannot restore bone loss, strengthen their structure or increase their mechanical strength. Also, restoration of the proper shape and function of the spine, and protection from further fractures is impossible to achieve with radiotherapy alone. In the case of compression of the nervous structures, by the tumor masses, radiotherapy may result in a reduction of neurological deficits. However, effectiveness in cases where compression is caused by bone fragments is limited $[2,7,8]$.

Surgical treatment of lesions caused by multiple myeloma in the spine is controversial and has both advantages and disadvantages. The mechanical stabilization of the spine is not fully-effective due to insufficient bone tissue quality, and a lack of healing reactions. Bone union after the surgical procedure of stabilization is impossible. Surgery should be reserved for cases where urgent decompression of neurological structures is imperative, and for patients in long-term remission $[2,7,9]$.
Remarkably effective in treating myeloma lesions of the spine are vertebro- and kyphoplasty. These methods allow for the strengthening of the damaged vertebra, and prevent spinal kyphotisation and its further consequences. Kyphoplasty allows for the partial re-establishment of the original height of the collapsed vertebra, and therefore is effective in patients with fractures. Both methods successfully decrease pain. The treatment does not necessitate interruption in chemotherapy and procedures can be performed under local anesthesia. 3-4 vertebrae can be operated on simultaneously. Contraindications to vertebroplasty are symptoms of spinal canal stenosis, neurological deficits and haemorrhagic difficulties [2, 10-13].

The study evaluates the oncological and functional outcomes after surgical treatments of the patients with multiple myeloma involving the vertebral column.

\section{Methods}

Over the period 2010-2014, a total of 542 patients with spinal tumours were treated in our facility, of which 474 were operated on. In 129 patients the indication for surgery was multiple myeloma. The majority of patients $82 / 129$ (64\%) were women. The average age of the women was 72 , and 68 years for the men.

The most common site of involvement by widespread metastatic lesions was the thoracic spine. Metastases in the lumbar spine were less common. In the cervical spine, there was only one patient with a tumor in the second and the third body of the vertebra - Fig. 1 .

Isolated lesions involving single vertebrae were rare; remarkable only in 10 out of 129 (8\%) patients. The regions most often invaded by metastases were the vertebral bodies (98/129 patients), less frequently the posterior elements. Soft tissue masses were noted in 31 out of 129 (24\%) patients. Spinal canal stenosis occurred in 54/129 (42\%) patients. Pathological fractures were diagnosed in 98 of the 129 (76\%) patients. Symptoms of spinal instability were seen to afflict $80 / 129(62 \%)$ of the patients.

The functional results of patients were evaluated according to the Karnofsky scale, and pain intensity was measured in a VAS score before and after the surgery.

The pain suffered by the patients was of various characters and degrees, it was caused by the instability of the spinal column as a component factor in 75 out of 129 (58\%) patients, and in 39 out of 129 patients $(30 \%)$, the causes were neuralgic. Biological pain brought on by by increased intraosseous pressure, occurred in 48 out of 129 (37\%) patients. The severity of this pain was assessed in the patients prior to surgery and on postoperative day 7 and 14, using VAS. More severe symptoms were observed in 


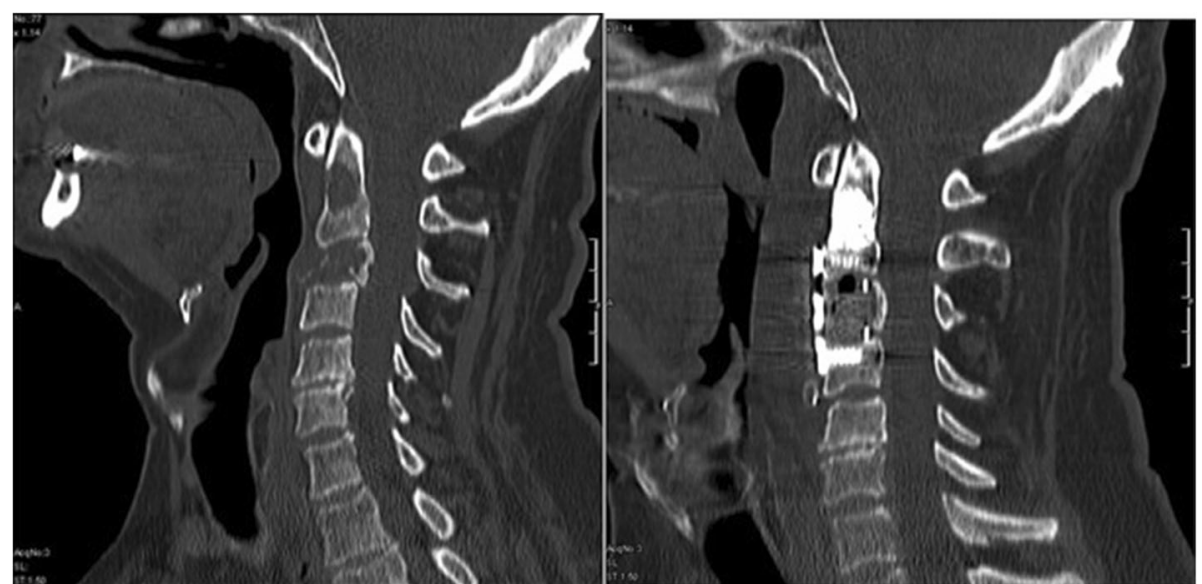

Fig. 1 Myeloma metastasis to C2 and C3 (a) and radiograms after surgery (vertebral body prosthesis of C3 and the plate fixation, dens axis vertebroplasty) (b)

the patients with vertebral fractures and spinal instability - Fig.2.

The study also assessed the pre- and postoperative neurological status of patients with special consideration being taken concerning the strength of the muscles, sensory abilities, sphincters function, and the occurrence of symptoms from compressed nerve roots. Table 1 demonstrates baseline clinical characteristics and examination findings in patients with myeloma metastases of the vertebral column.

A total of 129 patients with myeloma metastases of the vertebral column underwent surgery.

A spine fixation was performed in 56 patients. Four patients underwent resection of the vertebral body, in conjunction with prosthesis implantation and lateral stabilization. In 8 patients, the surgery was performed through 2 approaches, and involved vertebral body resection, prosthesis implantation and percutaneous stabilization of the spine through the posterior

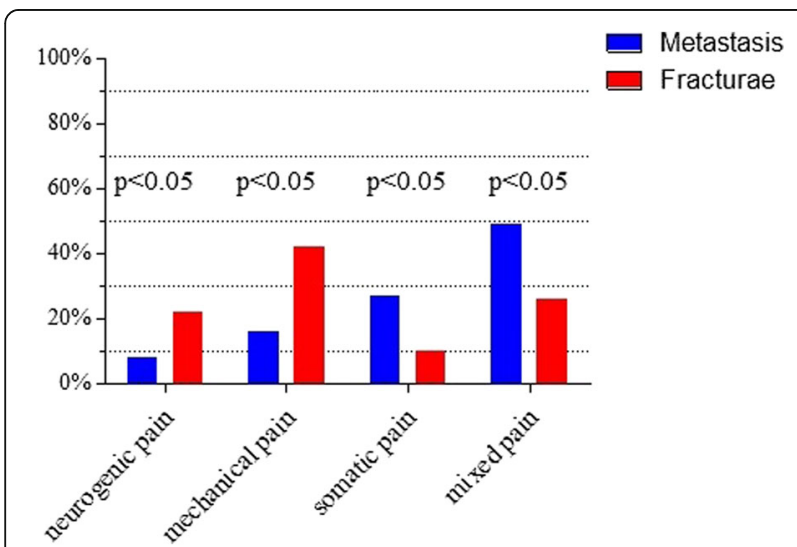

Fig. 2 The type of pain in patients depending on a pathological fracture of the vertebral column approach. Forty four patients were operated on through the posterior approach. Extensive laminectomy, combined with stabilization of the spine was performed. Each time, stabilization encompassed two vertebrae above and two vertebra below the malignant lesion. Indications for open spinal surgery were: the presence of a large soft tissue mass, neurological deficits, spinal instability, central or lateral stenosis, extensive spinal axis disturbances and vertebral collapse over $50 \%$. Generally, open spinal surgery was performed when vertebroplasty was contraindicated, and patients were in good general condition. Contraindications to the open surgical proceedure were: a patients poor overall health condition, a life

Table 1 Baseline clinical characteristics and examination findings in patients with myeloma metastases in the vertebral column. $N=129$

Variables N (\%)

Fracture 98 (76)

Multi level involvement

Vertebral body involvement

Spinal canal stenosis

Soft tissue mass

Orthopedic examination elements

Spinal axis disorder

Reflex scoliosis

Increased paraspinal muscle tension

Spinal pain on spinous processes

Pain on axial compression by pressing the head

Reduced mobility of the spine

$114(88)$

Pain on movement

$98(76)$

Results are presented as a number with a percentage 
expectancy of less than 3 months, active infection at the site of surgical access.

Vertebroplasty was performed in 73 patients. In total, 112 vertebrae were cemented - maximum of 3 vertebrae at the same time. The procedures were performed under general anaesthesia in 63 out of $73(86 \%)$ patients and under local anaesthesia in 10/73 (14\%) patients. The needle was always inserted one-sidedly into the vertebral body, through the pedicle and under X-ray guidance. Cementation through the bilateral approach was not performed. The patients scheduled for vertebroplasty were those with metastases with no fractures, or with fractures but without any substantial deformations of the spine. It was assessed whether there were no losses in the anterior wall of the spinal canal. Patients with vertebral compression (over $50 \%$ of the initial group) and patients with recently experienced neurological symptoms or spinal canal stenosis were not scheduled for a vertebroplasty.

Adjuvant radiation therapy was administered to 47 out of 73 (64\%) patients after vertebroplasty and 38/56 (68\%) patients after surgical intervention.

Quantitative variables were expressed as means ( $\mathrm{x}$ ) with standard deviations. To compare the effects of different treatments, an options paired Student's t-test was used. The sub-group differences were tested using a Wilcoxon test. The categorical variables were expressed as percentages. The inter-group differences were tested using the $x^{2}$ test. The inter-group overall survival rates were compared with a Log-Rank test and presented as the Kaplan-Meier curves. All statistical analyses were performed by employing Statistica 10. A value of $P<0.05$ was considered statistically significant.

The research was performed in accordance with the declaration of Helsinki. As this retrospective analysis consists of anonymised clinical routine data, the Research Ethics Committee deems the application for and issue of Ethics approval, as not necessary. All the patients gave their written consent to the use of data for our research.

Contact information of Ethics committee: Ethics Committee in Cracov, ul Krupnicza 11a 31-123 Cracov, tel. $+48,126,191,712$, fax $+48,124,225,755$.

\section{Results}

The average follow-up was 31 months ( $\min 18$, max 48). In the final review it was found that 53 patients after vertebroplasty had survived, compared to 27 after surgery. The median survival was 34 months. On average, patients after vertebroplasty survive 42 months compared to 23 after surgery. Survival rates are exhibited in Fig. 3, according to the type of vertebral involvement. Local recurrence of the disease was observed in 12 patients who underwent surgery.

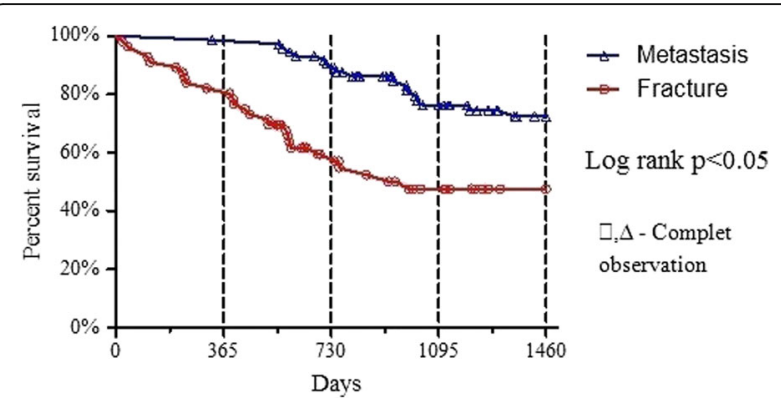

Fig. 3 Survival of the patients according to type of vertebral involvment. $N=129$

It was assessed whether the following factors affect survival: age, time of initial diagnosis, post-operative radiotherapy, stage of disease and biochemical markers. Three significant factors (age over 65 years, initial diagnosis over 3 years and III stage of disease) were statistically related to survival - Table 2 .

The mean duration of the surgeries, utilizing the anterior approach, was $120 \mathrm{~min}$ (range: $90-170 \mathrm{~min}$ ), and $80 \mathrm{~min}$ (range: $50-120 \mathrm{~min}$ ) employing the posterior approach. The average duration of the surgeries through both of the approaches was 220 min (range: 120$300 \mathrm{~min}$ ). Patients were hospitalized between 8 and 22 days (14 days on average). The mean vertebroplasty time was $35 \mathrm{~min}$ (range: 25-60). The hospital stay time was 2 days, on average. There was also an assessment of the frequency of the occurrence of potential contraindications to vertebroplasty - Table 3 .

The functional results were evaluated as, the pain rate in a VAS score and performance in a Karnofsky score - Table 4.

In 10 patients out of 21 with paresis, neurological functions improved. Neurological status were described in Table 5.

There were infrequent postoperative complications after vertebroplasty: asymptomatic cement leakage into the spinal canal occurred in two patients and pulmonary microembolism in one patient. After the surgery, 3 patients suffered from impaired wound healing, and two required revision surgery. The wounds healed in all of the patients. There was no deterioration in neurological status after the surgery, and there was no evidence of loosening or mechanical damage to the surgical implants - Table 6.

\section{Discussion}

Myeloma is a haematopoietic malignancy, particularly frequently diagnosed in the 6-7th. decade of life. Diagnosis of myeloma is based on radiological examinations and on detection of monoclonal immunoglobulines or light chains in the urine. Confirmation of a diagnosis is based on the histopathological examination of the patient's bone 
Table 2 Analysis of numerous factors that might be related to overall survival

\begin{tabular}{|c|c|c|}
\hline & Number of patients & $p$-value \\
\hline \multicolumn{3}{|l|}{ Age } \\
\hline$<65$ years & $43(33 \%)$ & $<0.05$ \\
\hline$>65$ years & $86(67 \%)$ & $<0.05$ \\
\hline \multicolumn{3}{|c|}{ Stage of disease (Salmon-Durie) } \\
\hline । & $8(6 \%)$ & Ns \\
\hline$\|$ & $20(16 \%)$ & Ns \\
\hline III & $101(78 \%)$ & $<0.05$ \\
\hline \multicolumn{3}{|l|}{ Radiotherapy } \\
\hline Yes & $85(66 \%)$ & Ns \\
\hline No & $44(34 \%)$ & Ns \\
\hline \multicolumn{3}{|c|}{ Time to initial diagnosis } \\
\hline$<1$ year & $23(8 \%)$ & Ns \\
\hline $1-2$ years & $48(37 \%)$ & Ns \\
\hline$>3$ years & 71 (55\%) & $<0.05$ \\
\hline \multicolumn{3}{|l|}{ CRP level } \\
\hline$<5 \mathrm{mg} / \mathrm{l}$ & $91(70 \%)$ & Ns \\
\hline$>5 \mathrm{mg} / \mathrm{l}$ & $38(30 \%)$ & Ns \\
\hline \multicolumn{3}{|c|}{ Peripheral blood stem cell transplantation } \\
\hline Yes & $71(55 \%)$ & Ns \\
\hline No & $58(45 \%)$ & Ns \\
\hline \multicolumn{3}{|c|}{ Lactate dehydrogenase } \\
\hline$<240 \mathrm{U} / \mathrm{l}$ & $93(72 \%)$ & Ns \\
\hline$>240 \mathrm{U} / \mathrm{l}$ & $36(28 \%)$ & Ns \\
\hline \multicolumn{3}{|c|}{ Beta-2 microglobulin } \\
\hline$<3.5 \mathrm{mg} / \mathrm{l}$ & $8(6 \%)$ & Ns \\
\hline $3.5-5.5 \mathrm{mg} / \mathrm{l}$ & $31(24 \%)$ & Ns \\
\hline$>5.5 \mathrm{mg} / \mathrm{l}$ & 90 (70\%) & Ns \\
\hline
\end{tabular}

marrow, following sternum or iliac crest trepanobiopsy, supplemented with an evaluation of the tumour $[2,12,13]$. In the last few years many authors have worked to determine the suitability of KISS1R for myeloma multiplex diagnosis. In the future it could be usefull for detecting elary changes in the bone microenvironment and the patient's response to treatment [14]. The treatment of myeloma consists of polychemotherapy complemented with radiotherapy. This allows for long-term remissions, even for many years. In the past, spinal lesions were treated non-surgically, with radiotherapy only [2, 12]. The efficiency of radiotherapy in palliating pain was $75-100 \%$ in several studies. Uni and multivariate binary logistic regresion analysis improved pain relief, was closely associated with the patients age and the total radiotherapy doses. Recalcification was observed in $48 \%$ of the treated cases and was associated with the total radiotherapy doses $[15,16]$.
Table 3 Frequency of potential contraindications to vertebroplasty in our group of patients

\begin{tabular}{|c|c|c|}
\hline $\begin{array}{l}\text { Potential contraindications } \\
\text { to vertebroplasty }\end{array}$ & $\begin{array}{l}\text { Patients qualified } \\
\text { to vertebroplasty } \\
n=73 \\
n / \%\end{array}$ & $\begin{array}{l}\text { Patients qualified to } \\
\text { spine stabilizations } \\
n=56 \\
n / \%\end{array}$ \\
\hline $\begin{array}{l}\text { Impairment of the } \\
\text { neural elements }\end{array}$ & No & $21(37 \%)$ \\
\hline Cauda equine syndrome & No & $6(11 \%)$ \\
\hline Spine kyphosis & $12(16 \%)$ & $56(100 \%)$ \\
\hline $\begin{array}{l}\text { Fractures with obstructing } \\
\text { plasmocytoma }\end{array}$ & No & $31(55 \%)$ \\
\hline Retropulsed bone & No & $56(100 \%)$ \\
\hline Vertebra plana & No & $15(27 \%)$ \\
\hline $\begin{array}{l}\text { Disruption of the posterior } \\
\text { vertebral body cortex }\end{array}$ & No & $54(96 \%)$ \\
\hline Unstable spine & $47(64 \%)$ & $56(100 \%)$ \\
\hline Metal or PMMA alergy & No & No \\
\hline Coagulopathy & No & No \\
\hline Neutropenia & $6(8 \%)$ & $2(4 \%)$ \\
\hline Cardio-pulmonary insufficiency & No & No \\
\hline Radiotherapy before surgery & $2(3 \%)$ & $4(7 \%)$ \\
\hline Skin infections & No & No \\
\hline
\end{tabular}

Lecouvet et al. reported new focal marrow lesions in $4 \%$ of irradiated and $27 \%$ of non-irradiated vertebras and new fractures in $5 \%$ of irradiated and $20 \%$ of non-irradiated vertebras [17]. Currently, various methods of surgical treatment are increasingly being employed and radiotherapy is seen as an adjuvant. This creates the greatest opportunities for alleviating pain and adaquate physical functioning for the patient's long-term $[2,18]$.

The multiple myeloma is localized particularly often in the thoracic and lumbar region of the spinal column; within its vertebral bodies. The posterior elements are rarely involved. What is characteristic, apart from lytic bone lesions, is the occurrence of soft tissue masses which compress the adjacent organs or neurologic structures [2, 12]. Among other factors, this is the cause of the combination of two or three different types of pain in some patients. We have reported the frequent occurrence of neuropathic pain in patients without vertebral fractures. Also spine instability, that causes mechanical pain, in patients without fractures, is associated with damage to the spinal ligaments and spinal muscles.

It is imperative for adequate treatment, to diagnose the lesions as early as possible, in the vertebral column. In more than $90 \%$ of patients a clinical examination allows for the diagnosis of metastases in the spine. Radiological examinations permit an accurate assessment of their location and size, as well as aiding in treatment planning. In the case of minor 
Table 4 Mean results of the VAS score and the Karnofsky performance score in patients before and after surgery, and after different treatment methods

\begin{tabular}{|c|c|c|c|c|}
\hline \multirow[t]{2}{*}{ Treatment option } & \multicolumn{2}{|l|}{ VAS score } & \multicolumn{2}{|c|}{ Karnofsky score } \\
\hline & Preoperative & Postoperative & Preoperative & Postoperative \\
\hline Patients after vertebroplasty $N=73$ & $5,3( \pm 1.8)$ & $1,4( \pm 0.9)^{*}$ & $60( \pm 7.9)$ & $80( \pm 5.6)^{*}$ \\
\hline Patients after stabilization $N=56$ & $8.1( \pm 0.6)$ & $4.4( \pm 1.1)^{*}$ & $54( \pm 9.8)$ & $59( \pm 12.2)$ \\
\hline Anterior stabilization $N=4$ & $7.5( \pm 1.2)$ & $4.7( \pm 1.0)$ & $52( \pm 8.0)$ & $58( \pm 9.2)$ \\
\hline Posterior stabilization $N=44$ & $8.0( \pm 0.4)$ & $4.1( \pm 0.6)^{*}$ & $56( \pm 5.5)$ & $62( \pm 5.5)$ \\
\hline Combine stabilization $N=8$ & $9.2( \pm 1.6)$ & $4.5( \pm 0.9)^{*}$ & $49( \pm 11)$ & $55( \pm 10)$ \\
\hline Vertebroplasty vs. Stabilization & $p=<0.05$ & $p=<0.05$ & NS & $p=<0.05$ \\
\hline
\end{tabular}

Results are presented as a mean \pm standard deviation

${ }^{*} p<0.05$

lesions, it is sufficient to conduct a radiographic examination and CT scan of the vertebral column. Large soft-tissue tumours, and those causing neurological deficits, require diagnosis through MRI [2, 19-21].

Qualification for treatment is multifaceted and requires the cooperation of the orthopedic surgeon, hematologist, radiologist, anesthesiologist, and radiotherapist. It is important to establish a prognosis, estimate the stage of the disease, assess the general condition of the patient, discover any chronic diseases and the possibility of complementary therapies.

Patients with lytic lesions in the vertebrae should be scheduled for vertebroplasty as early as possible, before pathological fractures can occur. This allows for the retention of the normal shape of the vertebra and the whole vertebral column, successfully eliminates pain associated with malignant disease and posture pain $[2,22,23]$. Kado et al. showed statistically significant mortality decreased in patients without vertebral fractures, compared to patients with five or more fractures [24]. Patients with fractures and no major spinal deformities should also be scheduled for vertebroplasty or kyphoplasty as soon as possible. After the surgery, adjuvant radiotherapy can be given to limit the progression of the disease $[2,25,26]$. In their study Dudeney et al. demonstrated that over $80 \%$ of patients experienced pain relief after vertebral augmentation [10].
Vrionis et al. in his study reported the significant difference in pain intensity after vertebroplasty in $95 \%$ of patients. Cement leakage was detected in $13 \%$ of patients [27]. Fourney et al. reported the complete pain reduction in $84 \%$ of patients after vertebroplasty. Cement leakage was detected in $9.2 \%$ of the patients [28].

In our group of patients, $78 \%$ were operated on in the stage III of the disease. Open spine surgeries and vertebroplasty in the early stages of the disease were rare. The reason may be due to a lack of clear indications for different treatment methods including radiotherapy, vertebroplasty and surgery. Oncologist, Hematologist and Orthopedists have different experiences in the treatment of myeloma. Furthermore, patients often decline to undergo preventive surgical treatment.

Patients with large tumors causing pressure on the nerve structures, the destruction of major bones and damage to the anterior wall of the vertebral canal, as well as spinal instability, are scheduled for decompression surgery and stabilization of the spine. It should be kept in mind that the risk of complications in patients who underwent surgery immediately following radio- and chemotherapy is high. The widest possible decompression of neural structures creates an opportunity to reverse the neurological deficits. Multi-segmental stabilization of the spine is recommended, as it allows for the rehabilitation of

Table 5 Neurological status in patients before and after the surgery, and after different treatment methods

\begin{tabular}{|c|c|c|c|c|}
\hline \multirow[t]{2}{*}{ Neurological Status } & \multicolumn{2}{|c|}{ Posterior stabilization $N=44$} & \multicolumn{2}{|c|}{ Combine stabilization $N=8$} \\
\hline & Preoperative & Postoperative & Preoperative & Postoperative \\
\hline Frankel A & $5(11)$ & $3(7)$ & $1(12)$ & 0 \\
\hline Frankel B & $5(11)$ & $2(5)^{*}$ & 0 & $1(12)$ \\
\hline Frankel C & $3(7)$ & $2(5)$ & $1(12)$ & $1(12)$ \\
\hline Frankel D & $2(5)$ & 0 & 0 & 0 \\
\hline Sensory impairments & $4(9)$ & $2(5)^{*}$ & 0 & 0 \\
\hline
\end{tabular}

Results are presented as a number with a percentage

${ }^{*} p<0.05 x^{2}$ 
Table 6 Systemic complication after surgery in patients with myeloma metastases in thevertebral column

\begin{tabular}{llll}
\hline Treatment option & Systemic complication & & Local recurrence \\
\cline { 2 - 4 } & Surgical wound infections & Pulmonary embolism & (1.3) \\
\hline Patiens after vertebroplasty $N=73$ & 0 & 2 (3.6) & 12 (22) \\
Patients after stabilization $N=56$ & $3(5)$ & &
\end{tabular}

Results are presented as a number with a percentage

the patients immediately after surgery. Bone fusion is unlikely to occur. It is generally agreed to avoid the use of bone grafts due to the significantly increased risk of wound infection. Radical excision is possible when the tumours are well demarcated. In place of the removed vertebral body, a titanium prosthesis or bone cement may be inserted [2, 29-33]. The majority of studies for open surgery qualified patients with neurological defects $-81 \%$ of patients [34]. After surgical treatment of metastases from multiple myeloma, many studies have reported an increase in the quality of life and survival of their patients. Complete pain reduction was observed in $76-100 \%$ of patients, and neurological status improvement in $50-76 \%$ of patients [34-36]. Zeifang et al. and Rompe et al. showed neurological improvement in up to $80 \%$ of patients with myeloma, following the combined anterior and posterior approaches. $91 \%$ of patients confirmed a reduction in pain, and 57\% experienced improvement in mobility [36, 37]. Total complication rates after spinal surgery were ranked from 10 to $52 \%$ $[34,38]$. Pascal-Moussellard et al. reported the observance of $19 \%$ of complications after surgery, with the most common being difficulty in wound healing - $11 \%$ and infections - 10\%. Trombo-embolic complications occurred in $11 \%$ of patients. Neurological function detoriation was reported in $3 \%$ of patients. No damage to implants was observed. [39].

In our patient group the incidence of complications were very low. This was probably related to our respect of the indications and contraindications to different surgical techniques. The correct and careful surgical technique, experience and good cooperation of the therapeutic team, seems to be the key to obtaining desirable treatment results. Very important is the proper visualisation of the tumour morphology in CT and MRI scans. It allows for the planning of the operating technique details, and for the avoidance of complications. In our study the best results were achieved by patients without spine fractures, who were treated by vertebroplasty. The pain intensity rated on a VAS score, Karnofsky performance status and survival were significantly increased. The reason may be due to the qualification of patients to vertebroplasty, in the earlier stages of the disease than to open spine surgery. Age over 65 years, time to initial diagnosis over 3 years and III stage of disease, were remarked as being statistically related to survival. The author postulates that the early diagnosis of spinal myeloma metastases is a condition necessary for the achievement of a successful treatment outcome.

\section{Conclusions}

Multiple myeloma spine metastases treatement requires a multidisciplinary, comprehensive approach and early diagnosis which is essential to achieve the desired results of treatment. Vertebroplasty, as advised, should be performed as early as possible. Both the functional and oncological results after vertebroplasty are beneficial and the complication rates are low. Three relevant patient factors: age over 65 years, initial diagnosis over 3 years and III stage of disease were significantly and statistically related to survival.

\section{Abbreviations \\ BJP: Bence Jones Proteins; ESR: Erythrocyte Sedimentation Rate; PMMA: Polymethyl methacrylate; VAS: Visual Analogue Scale}

\author{
Acknowledgements \\ None. \\ Funding \\ No fundings.
}

Availability of data and materials

All the necessary information are contained in the text. All included in study patients data are available only as paper document in polish language store in hospital archives. Therefore digital availability of patients data are limited.

\section{Authors' contributions}

I am the sole author of this work. My contribution to the work concerned: concept, design, data collection and analysis, thesis preparation, revision work, approval final manuscript.

\section{Authors' information}

I'am the head of the Oncological Orthopedics Department in Podkarpackie Oncological Center in Brzozów, Poland. I have alredy published over 30 papers in oncological field and a book.

\section{Ethics approval and consent to participate}

The research has been performed in accordance with the declaration of Helsinki. As this retrospective analysis consists of anonymised clinical routine data, the Research Ethics Committee deems the application for and issue of an Ethics approval not necessary.

All the data were anonymised before the author started research (had access to the data).

All the patients gave a written consent to the use of data for research. Name of Ethics committee: Ethics Committee in Cracov, ul Krupnicza 11 a 31-123 Cracov, tel. $+48,126,191,712$, fax $+48,124,225,755$. 


\section{Consent for publication}

Not applicable.

\section{Competing interests}

The authors declare that they have no competing interests.

\section{Publisher's Note}

Springer Nature remains neutral with regard to jurisdictional claims in published maps and institutional affiliations.

Received: 18 March 2017 Accepted: 16 August 2017

\section{Published online: 23 August 2017}

\section{References}

1. Dickman CA, Fehlings MG, Gokaslan ZL. Spinal cord and spinal column tumors principles and Practise. Thieme. 2004:303-33.

2. Guzik G. Przerzuty do kręgosłupa - diagnostyka i leczenie. Bielsko Biała: Alfa Medica Press; 2015.

3. Bilsky MH, Azeem S. Multiple myeloma: primary bone tumor with systemic manifestations. Neurosurg Clin N Am. 2008;19:31-40.

4. Fisher CG, DiPaola CP, Ryken TC, et al. A novel classification system for spinal instability in neoplastic disease: an evidence-based approach and expert consensus from the spine oncology study group. Spine. 2010:35:1221-9.

5. Galasko CSB, Norris HE, Crank S. Spinal instability secondary to metastatic cancer. J Bone Joint Surg. 2000;82A:570-6.

6. Wise JJ, Fischgrund JS, Herkowitz HN, Montgomery D, Kurz LT. Complication, survival rates, and risk factors of surgery for metastatic disease of the spine. Spine. 1999;24:1943-51.

7. Tomita K, Kawahara N, Kobayashi T, Yoshida A, Murakami H, Akamaru T. Srgical strategy for spinal metastases. Spine. 2001;26:298-306.

8. Asdourian PL. Metastatic disease of the spine. W: H. Bridwell, RL De Wald. The Textbook of Spinal Surgery. II wyd. Philadelphia: Lippincott - Raven Publishers, 1997:2007-2050

9. Kim DH, Chang UK, Kim SH, Bilsky MH. Tumors of the spine. Philadelphia: Saunders Elsevier; 2008.

10. Dudeney S, Lieberman IH, Reinhardt MK, Hussein M. Kyphoplasty in the treatment of osteolytic vertebral compression fractures as a result of multiple myeloma. J Clin Oncol. 2002;20:2382-7.

11. Atalay B, Caner H, Gokce C, Altinors N. Kyphoplasty: two years of experience in a neurosurgery department. Surg Neurol. 2005;64:72-6.

12. Durie BGM. New approaches to treatment for multiple myeloma: durable remission and quality of life as primary goals. Clin Lymphoma Myeloma. 2005;6:181-90

13. Durie BGM, Kyle R, Belch A, Bensinger W, Blade J, Boccadoro $M$, et al. Myeloma management guidelines: a consensus report from the scientific advisors of the international myeloma foundation. Hematol $J$ 2003:4:379-98.

14. Dotterweich J, Tower RJ, Brandl A, Muller M, Hofbauer LC, Beilhack A, et al. The KISS1 receptors as in vivo microenvironment imagining biomarker of multiple myeloma bone disease. PLoS One. 11(5):e0155087. 10.1371/journal pone.0155087.

15. Talamo G, Dimaio C, Abbi KKS, et al. Current role of radiation therapy for multiple myeloma. Front Oncol. 2015;5(40):1-8.

16. Bolke E, Matuschek C, Gripp S, et al. Effects of radiotherapy in the treatment vof multiple myeloma: a retrospective analysis of a single institution. Radiat Oncol. 2015:10(71):1-19.

17. Lecouvet F, Richard F, Vande BB, et al. Long-term effect of localized spinal radiation therapy on vertebral farctures and focal lesions appearance in patients with multiple myeloma. Br Journal of Haematol. 1997;96:743-5.

18. Gerszten PC, Welch WC. Combined percutaneous transpedicular tumor debulking and Kyphoplasty for pathological compression fractures. Technical note J Neurosurg Spine. 2007:6:92-5.

19. Sundaresan N, Rosen G, Boriani S. Primary malignant tumors of the spine. Orthop Clin North Am. 2009:40:21-36

20. Harrigton KD. Metastatic disease of the spine. J Bone Joint Surg 1986;68(A):1110-5.

21. Boriani S, Weinstein JN, Biagini R. Spine update: primary bone tumors of the spine: terminology and surgical staging. Spine. 1997;22:1036-44.
22. Lane JM, Hong R, Koob J, Kiechle T, Niesvizky R, Pearse R, et al. Kyphoplasty enhances function and structural alignment in multiple myeloma. Clin Orthop. 2004;426:49-3.

23. Hentschel SJ, Burton AW, Fourney DR, Rhines LD, Mendel E. Percutaneous vertebroplasty and kyphoplasty performed at a cancer center: refuting proposed contraindications. J Neurosurg Spine. 2005;2:440-6.

24. Kado DM, Browner WS, Palermo L, Nevitt MC, Genant HK, Cummings SR. Vertebral fractures and mortality in older women: a prospective study. Study of osteoporotic fractures research group. Arch Intern Med. 1999;159:1215-20

25. Crandall D, Slaughter D, Hankins PJ, Moore C, Jerman J. Acute versus chronic vertebral compression fractures treated with kyphoplasty: early results. Spine J. 2004:4:418-24.

26. Lieberman I, Reinhardt MK. Vertebroplasty and kyphoplasty for osteolytic vertebral collapse. Clin Orthop. 2003:415S:S176-86.

27. Vrionis FD, Hamm A, Stanton N, et al. Kyfoplasty for tumor associated spinal fractures. Tech Reg Anesth Pain Manag. 2005;9(1):35-9.

28. Fourney DR, Schomer DF, Nader R, et al. Percutaneous vertebroplast and kyphoplasty for painful vertebral body fractures in cancer patients. J Neurosurg. 2003;98(1):21-30.

29. Ecker RT, et al. Diagnosis and treatment of vertebral column metastases Mayo Clinic Proc. 2005:80:1177-86.

30. Weigel B, Maghsudi M, Neumann C, Kretschmer R, Muller FJ, Nerlich M. Surgical management of symptomatic spinal metastases. Postoperative outcome and quality of life. Spine. 1999;21:2240-6.

31. Rose SP, et al. Metastatic disease in the thoracic and lumbar spine: evaluation and management. J Am Acad Orthop Surg. 2011;19:37-48

32. Kaloostian PE, Yurter A, Zadnik PL, et al. Current paradigms for metastatic spinal disease: an evidence-based review. Ann Surg Oncol. 2014;21:248-62.

33. Fourney DR, Frangou EM, Ryken TC, et al. Spinal instability neoplastic score: an analysis of reliability and validity from the spine oncology study group. J Clin Oncol. 2011;29:3072-7.

34. Bilsky MH, Lis E, Raizer J. The diagnosis and treatement of metastatic spinal tumor. The Oncolog. 1999:4:459-69.

35. Khanna AJ, Reinhardt MK, Togawa D, Lieberman IH. Functional outcomes of Kyphoplasty for the treatment of osteoporotic and osteolytic vertebral compression fractures. Osteoporos Int. 2006:17:817-26.

36. Zeifang F, Zahlten-Hingfurange A, Goldschmidt $\mathrm{H}$, et al. Long-term survival after surgical intervention for bone disease in multiple myeloma. Ann Oncol. 2005;16(2):222-7.

37. Rompe JD, Eysel P, Hopf C, et al. Metastatic spinal cord compressionoptions for surgical treatment. Acta Neurochir. 1993;123:135-40.

38. Gokaslan ZL, York JE. Transthoracic vertebrectomy for metastatic spinal tumors. J Neurosurg. 1998:89:599-609.

39. Pascal-Moussellard H, Broc G, Pointillart V, et al. Complications of vertebral metastasis surgery. Eur Spine J. 1998;7:438-44.

\section{Submit your next manuscript to BioMed Central} and we will help you at every step:

- We accept pre-submission inquiries

- Our selector tool helps you to find the most relevant journal

- We provide round the clock customer support

- Convenient online submission

- Thorough peer review

- Inclusion in PubMed and all major indexing services

- Maximum visibility for your research

Submit your manuscript at www.biomedcentral.com/submit
) Biomed Central 